\title{
The benefits of
}

\section{mentorship for the dental team}

By Joanne Brindley ${ }^{\top} M A$, FHEA, PGCLTHE, RDT, RDH

This article:

- Helps registrants to prepare for the enhanced CPD

- Identifies the benefits of supporting one another in continued professional development

- Overviews the qualities required for an effective mentor

- Highlights the disadvantages of less formal online activities

- Suggests how mentorship can positively impact on the workplace.

\section{Becoming a reflective practitioner}

Becoming a reflective practitioner provides an opportunity to become an autonomous and self-directed professional. It facilitates the development of good quality care by stimulating personal and professional growth by addressing the gap between evidencebased theory and practice, underpinned by the prerequisite of insight in our past, current and future practice. In 2017 the General Dental Council (GDC) plans to transition to new Continued Professional Development rules which will change the CPD requirements for registrants, known as enhanced CPD. ${ }^{1}$ Heralding the mantra of Rolfe ${ }^{2}$ it is now no longer enough for professionals to know just 'what we do and how we do it', that a professional must be able to evidence the rational processes behind their decisions and judgements, to be able to demonstrate how they know. One way of addressing this is to ensure that professionals do not just have the skills, or indeed are able to demonstrate the skills to be reflective in action (show-how), but also develop a skill

' Senior Dental Care Professional Teaching Fellow, The University of Portsmouth Dental Academy, William Beatty Building, Hampshire Terrace, PO1 2QG 
set that allows them to reflect on action (know-how) via an evidence-based approach which underpins their individual practice. In developing reflective skills registrants may find it useful to use another, perhaps more experienced, member of the dental team to act as a guide ${ }^{3}$ or mentor. Schrubbe ${ }^{4}$ describes mentors as people who are able to see more in you than you see in yourself. They assist you in creating a vision and development plan that maximises your own strengths, abilities and potential for growth. An effective mentor is able to inspire confidence in others, pushing them to their limits in order to facilitate them achieving their greatest potential. Mentorship can be viewed as an effective way of guiding fellow members of the dental team through their 'river of practice.'

\section{The skills of a mentor}

The skills required by workplace mentors are: active listening skills, questioning and provision of information, feedback, facilitation of reflective skills and empathy. ${ }^{6}$ It is interesting to note the inclusion of empathy, which is also a quality that is sought in dental undergraduates as part of values based recruitment of NHS students. ${ }^{7}$ The

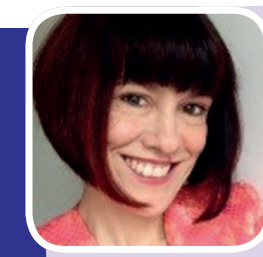

\section{Joanne Brindley}

Dentistry has been part and parcel of my entire working life. I qualified as a dental nurse back in 1991 and I have been a GDC registrant since 1994, working in both primary and secondary care environments as a dental hygienist and therapist. I joined the University of Portsmouth Dental Academy in 2005 and I am currently a Senior Dental Care Professional Academic Tutor, where I co-ordinate the pre-clinical activities for the first year BSc students in addition to coordinating the final year students research projects.

In 2012 I completed an MA in Learning and Teaching; my dissertation focused on the use of e-portfolios to aid in student learning. I am currently in the final stages of completing a Doctoral Thesis which is an illuminative evaluation of the use of reflection in undergraduate dental education.

I am passionate about enhancing DCP education, which is reflected in my current role as an Education Inspector for the General Dental Council. relationship of mentor and mentee should be non-directive and non-judgemental, respecting the subjective world of the mentee, ${ }^{6}$ with the caveat that they both (mentor and mentee) remain mindful of objective professional boundaries that are expected of a registrant. The positive benefits of clinical another in the safety of online forums. These can have the seductive quality of allowing people to gather multiple sources of support and information (via professional social networking platforms, un-calibrated discussion forums and general online hearsay) which could be inadvertently implemented

\section{'MENTORSHIP CAN BE VIEWED AS AN EFFECTIVE}

\section{WAY OF GUIDING FELLOW DENTAL TEAM MEMBERS}

\section{THROUGH THEIR “RIVER OF PRACTICE",}

mentorship have been acknowledged by the Department of Health ${ }^{8}$ who state that where these roles are embedded they have a flourishing and a demonstrable impact on patient care'. In the future new pathways could be explored with a view to creating supportive opportunities that triage those in more urgent need of mentorship support and foster opportunities to nurture the registrants who are floundering within their chosen profession.

\section{Enriching the development of skills}

Another way of enriching the development of reflective skills may be to use online mentorship support by embedding reflective logs and activities online via a virtual learning environment. Dabbagh ${ }^{9}$ has identified how 'Generation Xers' (those born 1960-80), have been replaced with the 'Generation Nexters' (those born 1980-2000), describing how learners are now being challenged with socially mediated online learning activities that de-emphasise independent learning and emphasise social interaction and collaboration. It is interesting that the 'classic' adult learner (independent, selfmotivated, remote) now appears to have an increasing requirement to evolve and manage a personal online presence, as part of their professional development, which could include opportunities for sharing their reflections and collaborate online as part of a peer mentorship programme. If online mentorship support is developed in the future it could become the foundation for encapsulating an ever-evolving lifelong learning journey. However, the use of online resources should not be confused with the informal process of covertly or overtly sharing or extolling information with one as part of a registrant's armamentarium, with the downside that the information may not necessarily be from a sound evidence-base. Davis $^{10}$ terms this information use as 'fragmentoring', describing that the downside of this type of activity is that not all of the 'mentoring participants' are aware of their role. If genuine mentors had knowingly been formally recruited to nurture their mentees they may well have implemented a more cautious stance opposed to more anecdotal information sharing. There is a danger that it may become all too easy for a practitioner to piece together fragments of information, weaving aspects that they personally prefer into their own (and complimentary) value system, opposed to having a more formal professional discussion with a mentor, with a view to resolving an identified problem or issue. The use of a more formalised system of synchronous or asynchronous online support system may well be a good way to provide the much needed support to developing practitioners, cultivating a safe and progressive environment in which to develop and hone their professional skill set, providing that professional boundaries and expectations are set.

\section{Professional reflection}

There is a synergy that exists between the trust required and the 'collegiate climate ${ }^{\text {'11 }}$ which is just as important as the technique and models deployed when undertaking professional reflection. It is of paramount importance that the mentor and mentee relationship is as supportive as possible. There is a requirement for both parties to be mindful of the element of risk and vulnerability the participating mentees may face. It can be just 
as embarrassing, or indeed empowering, for a colleague to be seen as a model of virtue to their peer, alongside the difficulties of exposing one's failures. A fine tightrope of balance must therefore be undertaken by a skilled mentor to ensure that the richness of this learning activity does not become a toxic environment leading to blame.

The prerequisites for mentorship to occur must be apparent in both stakeholders; the mentor must be keen to pursue, facilitate and support the needs of the mentee, and the mentee must be willing and keen to engage with this activity, which can become part of a much broader and effective development culture that encompasses the entire dental team, as demonstrated in Figure 1.

If the dental team, regardless of size, takes the time to listen to the views of one another (and their patients) via appreciative enquiry of ways to improve, this will allow them insight into their own individual strengths and weaknesses. If all of these positive aspects are developed within a culture that has a shared, safe and nurturing vision of practice, there is a tangible opportunity to lead to positive outcomes for all participants. Failure to integrate these positive attributes into the mentorship learning culture can lead to the development of a narrow view of the world,

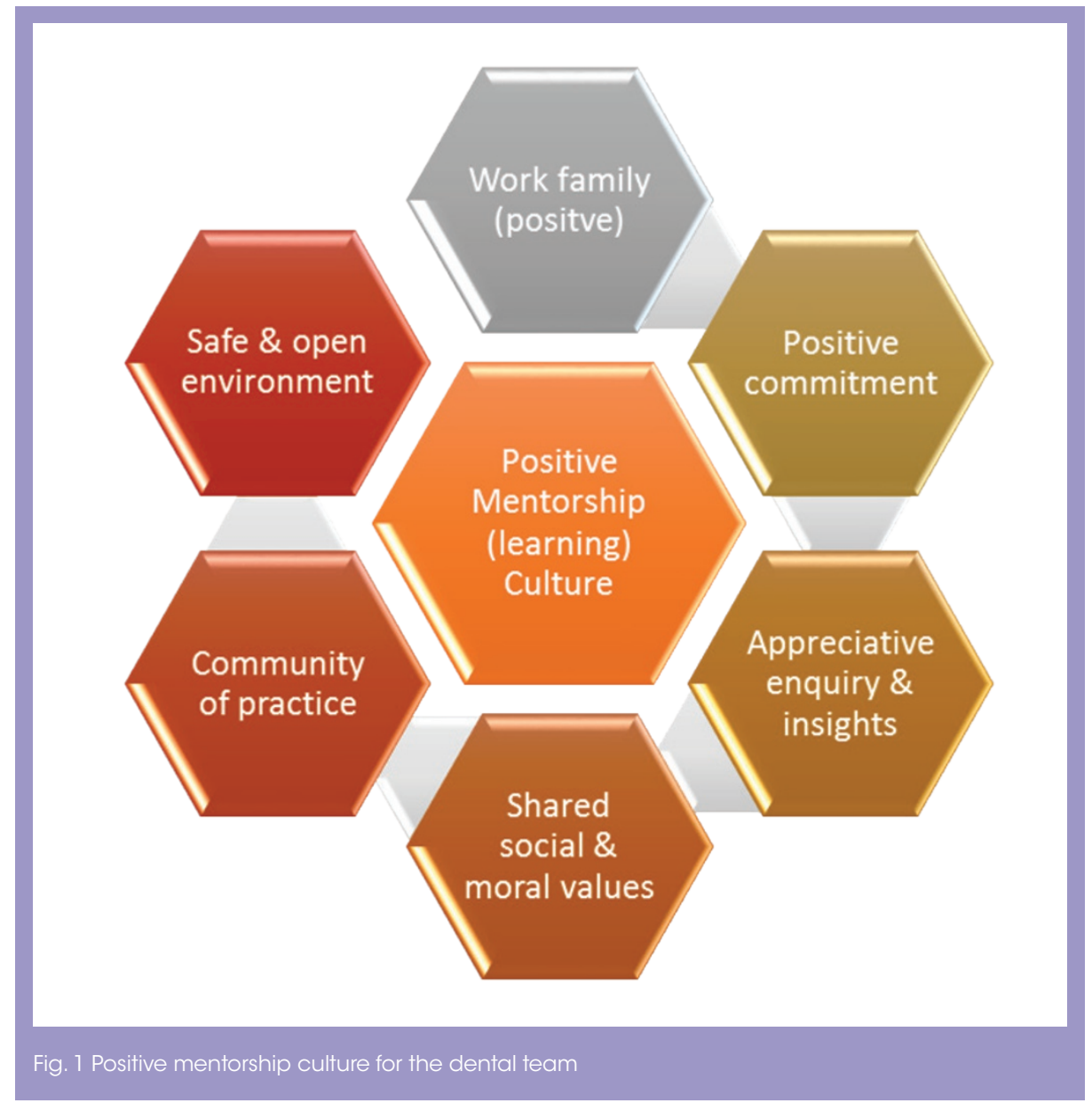

\section{THE MENTOR MUST BE KEEN TO SUPPORT THE}

\section{NEEDS OF THE MENTEE AND THE MENTEE}

\section{KEEN TO ENGAGE WITH THIS ACTIVITY.'}

which will ultimately limit the development of practical skills, suppress empathetic patient care and hamper emotional resilience.

Indeed, in these times of change it is important that we support one another, acknowledging, as the Berwick report ${ }^{12}$ recommends, that everyone should be able to come to work knowing that 'they will be treated with respect, supported to do their work and expand their skills, and be appreciated for what they do'. Perhaps it is time for us, as a profession to show some selfcompassion and empathy for one another, the same compassion that is afforded to patients up and down the country on a daily basis, by guiding and supporting one another as we sail down our 'river of practices ${ }^{35}$ as it meanders through our working lives.
1. General Dental Council. Enhanced CPD. 2016. Available at: https://www.gdc-uk.org/ Dentalprofessionals/CPD/Pages/EnhancedCPD.aspx (accessed February 2016)

2. Rolfe G. Beyond expertise: theory, practice and the reflective practitioner. In Rolfe G, Freshwater D, Jasper M. Critical reflection in nursing and the helping professions: a user's guide. Basingstoke: Palgrave Macmillan, 2001.

3. Johns C. Becoming a reflective practitioner, $3^{\text {rd }}$ ed. West Sussex: Wiley-Blackwell, 2009.

4. Schrubbe K F. Mentorship: a critical component for professional growth and academic success. J Dent Educ 2004; 68: 324-328.

5. Horan P. Framing the new reflection. Nurse Educ Pract 2005; 5: 255-257.

6. Brockbank A, McGill I. Facilitating reflective learning in higher education. Bristol: Taylor Francis, 1998.

7. Health Education England. Values Based
Recruitment Framework. Available at https:// www.hee.nhs.uk/printpdf/our-work/attractingrecruiting/values-based-recruitment (accessed April 2016)

8. Department of Health. Developing the role of the clinical academic researcher in the nursing, midwifery and allied health professions. London: TSO, 2012.

9. Dabbagh N. The online learner: characteristics and pedagogical implications. Contemporary Issues in Technology and Teacher Education 2007; 7: 217-226.

10. Davis J S. Building the positive workplace: a preliminary report from the field. In Linley A P, Harrington S, Garcea N (eds). pp 289-311. Oxford handbook of positive psychology and work. Oxford: Oxford University Press, 2010.

11. Fook J, Gardner F. Practising critical reflection - a resource handbook. Berkshire: McGraw Education, 2007.

12. National Advisory Group on the Safety of Patients in England. A promise to learn - a commitment to act. Improving the safety of patients in England. London: Williams Lea, 2013. Publication no. 2901213. Available at: https://www.gov.uk/government/uploads/ system/uploads/attachment_data/file/226703/ Berwick_Report.pdf (accessed April 2016).

bdjteam201685 